\title{
Drug use, mental health and problems related to crime and violence: cross-sectional study ${ }^{1}$
}

\author{
Heloísa Garcia Claro² \\ Márcia Aparecida Ferreira de Oliveira ${ }^{3}$ \\ Janet C. Titus ${ }^{4}$ \\ Ivan Filipe de Almeida Lopes Fernandes ${ }^{5}$ \\ Paula Hayasi Pinho $0^{6}$ \\ Rosana Ribeiro Tarifa ${ }^{7}$
}

\begin{abstract}
Objective: to investigate the correlation between disorders related to the use of alcohol and other drugs and symptoms of mental disorders, problems related to crime and violence and to age and gender. Methods: cross-sectional descriptive study carried out with 128 users of a Psychosocial Care Center for Alcohol and other Drugs, in the city of São Paulo, interviewed by means of the instrument entitled Global Appraisal of Individual Needs - Short Screener. Univariate and multiple linear regression models were used to verify the correlation between the variables. Results: using univariate regression models, internalizing and externalizing symptoms and problems related to crime/violence proved significant and were included in the multiple model, in which only the internalizing symptoms and problems related to crime and violence remained significant. Conclusions: there is a correlation between the severity of problems related to alcohol use and severity of mental health symptoms and crime and violence in the study sample. The results emphasize the need for an interdisciplinary and intersectional character of attention to users of alcohol and other drugs, since they live in a socially vulnerable environment.
\end{abstract}

Descriptors: Alcohol-Related Disorders; Substance-Related Disorders; Mental Health; Reproducibility of Results; Violence; Crime.

\footnotetext{
1 Paper extracted from doctoral dissertation "Validação do Instrumento 'Avaliação Global das Necessidades Individuais - Inicial'", presented to Escola de Enfermagem, Universidade de São Paulo, São Paulo, SP, Brazil. Supported by Fundação de Amparo à Pesquisa do Estado de São Paulo (FAPESP), Brazil, processes \# 2012/123873-7 e 2010/20741-7.

2 Doctoral student, Escola de Enfermagem, Universidade de São Paulo, São Paulo, SP, Brazil. Scholarship holder from Fundação de Amparo à Pesquisa do Estado de São Paulo (FAPESP), Brazil.

${ }^{3} \mathrm{PhD}$, Associate Professor, Escola de Enfermagem, Universidade de São Paulo, São Paulo, SP, Brazil.

${ }^{4} \mathrm{PhD}$, Researcher, Lighthouse Institute, Chestnut Health Systems, Bloomington, IL, United States.

${ }^{5}$ PhD, Adjunct Professor, Centro de Engenharia, Modelagem e Ciências Sociais Aplicadas, Universidade Federal do ABC, São Bernardo do Campo, $\mathrm{SP}$, Brazil.

${ }^{6}$ Post-doctoral fellow, Escola de Enfermagem, Universidade de São Paulo, São Paulo, SP, Brazil.

7 Master's student, Escola de Enfermagem, Universidade de São Paulo, São Paulo, SP, Brazil. Scholarship holder from Coordenação de Aperfeiçoamento de Pessoal de Nível Superior (CAPES) Brazil.
}

Corresponding Author: Heloísa Garcia Claro

Universidade de São Paulo. Escola de Enfermagem

Rua Dr. Enéas de Carvalho Aguiar, 419

Bairro: Cerqueira César

CEP: 05403-000, São Paulo, SP, Brasil

E-mail: heloisa.claro@usp.br
Copyright @ 2015 Revista Latino-Americana de Enfermagem This is an Open Access article distributed under the terms of the Creative Commons Attribution Non-Commercial License (CC BY-NC).

This license lets others distribute, remix, tweak, and build upon your work non-commercially, and although their new works must also acknowledge you and be non-commercial, they don't have to license their derivative works on the same terms. 


\section{Introduction}

The use of alcohol causes the death of 2.5 million people a year and has a significant causal role in the occurrence of 60 different types of diseases, in addition to causing damage to the health and welfare of the user's interaction people ${ }^{(1)}$. The global burden of health problems related to alcohol consumption reached in 2000 , equivalent to $4 \%$ of all morbidity and mortality occurred in the planet that year, indicating further, upward trend - taking into account the amount estimated in $1990(3.5 \%)^{(1)}$.

It is estimated that in Brazil, $7.3 \%$ of Gross Domestic Product (GDP) is spent annually on alcoholrelated problems. For the Brazilian GDP of the year 2010 , of $R \$ 3,439,997$ billion, the social cost related to problems due to alcohol abuse would reach the amount of R\$251,119 billion a year(2).

Data from the Global Status Report on Alcohol and Health 2011, World Health Organization - WHO, reveal that $18.7 \%$ of Brazil's population is composed of people who have never consumed alcohol and drugs, $31.8 \%$ of people who consume alcohol regularly and $50.5 \%$ of people who do not use alcohol for more than one year. In the United States of America - USA, the same report data show that $17.7 \%$ of the population consists of people who have never consumed alcohol and drugs, $16.9 \%$ - nearly half of Brazil's percentage - are people who consume alcohol regularly and $34.6 \%$ are people who do not consume alcohol for more than one year ${ }^{(1)}$.

In Brazil, approximately $12.3 \%$ of the population may be considered alcohol dependent, according to the criteria of the International Classification of Diseases-10 and the Diagnostic and Statistical Manual of Mental Disorders - DSM-IV, and the prevalence is of $17.1 \%$ among males and of $5.7 \%$ in the female population, showing high prevalence compared with other health conditions ${ }^{(2-3)}$.

About one in five people who use illegal drugs has criteria for the diagnosis of dependence, and these substances affect the perception, mood and consciousness of its users, which can affect the users' ability to exercise control over drug use. The result can cause addiction, leading to continued use, despite the damage caused. In addition to profound disability and loss of physical health, people with disorders caused by the use of Alcohol and Other Drugs (AOD) may suffer severely with psychological and psychosocial problems, interpersonal problems, job loss, learning disabilities, as well as legal problems $\mathbf{s}^{(2,4)}$.
Recent epidemiological studies show that mental disorders are the main cause of more than $10 \%$ of the lost years of healthy life and over $30 \%$ of all years lived with disability, and these disorders present high prevalence and often have chronic nature. Low recognition rates of cases and effective treatment exacerbates the problem, especially in poor or developing countries, like Brazil(5-6).

WHO estimates that, currently, in the world, 350 million people suffer from depression (Marcus M, 2012), 26 million people suffer from schizophrenia and 125 million people are affected by use of AOD. Approximately 844,000 people die from suicide every year ${ }^{(5)}$.

When users are approached and referred for treatment in the early stages of drug use, the cost savings may reflect even on the criminal justice costs, such as detention costs and other issues resulting from criminal actions in society. A study shows that the active market of drugs leads to inefficiency in the costs, favoring other crimes as crimes against property, parallel power, deaths and executions, secondary receiving markets, family breakdown, among others ${ }^{(7-8)}$.

The consequences of the misuse of alcohol and drugs go beyond those related to the damage to the health of the abusers (as the clinical situation worsens, more health services are used and more health interventions are performed). They also refer to public impact consequences, such as the use of the taxes paid by society to finance the actions of treating and preventing alcohol abuse. In addition, there is also a loss of productivity experienced by this same society as a result of health problems of individuals affected by this problem, since one of its consequences is the abandonment of work and accidents that can lead to physical disabilities and early death(2).

As evidenced in the literature mentioned above, there is a possible relationship between the gravity of the problems related to the use of AOD with mental health symptoms, crime and violence. Despite this, few studies have investigated this correlation in a quantitative fashion. This study aimed to find evidence to verify the correlation between the problems reported by individuals in the areas of mental health, crime and violence, and alcohol and drugs. Once verified this correlation, it is highlighted the importance of promoting actions aiming at the care of the individual holistically, supporting the needs that are closely linked and constitute the psychosocial field.

In this study, the instrument entitled Global Appraisal of Individual Needs - Short Screener (GAINSS) was used for measurement of the symptoms or 
emotional and behavioral problems related to substance use and involvement in crime and violence. The evaluation results in these conditions provide support guidelines to the clinical decision on the patient's needs, as well as diagnosis and treatment possibilities( ${ }^{(9)}$.

The aim of the study was to verify, on a sample of users of Psychosocial Care Centers AOD - CAPSad, the correlation between the reporting of symptoms related to the use of AOD (dependent variable) with the reporting of symptoms related to mental and emotional health, as well as reports of problems related to crime and violence.

\section{Methods}

This is cross-sectional study, in which 128 individuals were interviewed, by means of the GAINSS* instrument, in the post-reception phase, in a Psychosocial Care Center for Alcohol and Other Drugs in the city of São Paulo. It was approached individuals aged between 18 and 60 years, who used alcohol and/ or drugs and sought treatment at CAPSad.

The GAIN-SS instrument and the ABS system in Portuguese resulted from the matrix research called Development of the Brazilian version of the GAIN Assessment Building System software and Validation of the Global Appraisal of Individual Needs, for use in Brazil, conducted by the Study Group on Alcohol and other Drugs - GEAD of the Nursing School, University of São Paulo - EEUSP. In the mentioned research, it was carried out the translation and cultural adaptation of the GAIN-SS instrument into Portuguese spoken in Brazil, and instrument validation.

The results of this research showed that the instrument validated by the Rasch model, has internal consistency and performance compatible with the American version. The instrument measures 23 symptoms and when it was the last time that they happened (never, more than a year ago, 4-12 months ago, 2-3 months ago, or last month). This provides a score on the severity of the individual in 5 areas: internalizing symptoms, externalizing symptoms (which comprises the mental health area), substance use, crime and violence and total severity). Once the instrument is valid for use in Brazil, and measures the needs of the individual in all areas of interest, its use in this study is justified(10).
Internalizing symptoms are defined in the literature consulted as aspects related to depression, anxiety, traumatic stress and suicide. Externalizing symptoms are defined as attention deficit, hyperactivity disorder and conduct disorder(11).

The study was approved by the Research Ethics Committee of the Nursing School of the University of São Paulo (proposing institution) and by the Municipal Health Secretariat of São Paulo (co-participant institution), under Process CAE number 15450713.8.0000.5392.

The interviews** were conducted at CAPSad in the southern region of the city of São Paulo, in a comfortable environment, without interruption, preserving the privacy of the individual (with no possibility of other people listen to the interview), with the presence of the interviewer and interviewee only. The CAPSads offer full assistance, with individual care (medication, psychotherapy, guidance, etc.) and care in groups (psychotherapy, operative group, support and social activities), therapeutic workshops, visits and home care, family care, detoxification care and community activities, focusing on the integration and family and social integration(12).

During the period of data collection, 444 individual treatment plans were initiated in the service. Of these, 93 individuals were excluded because they sought treatment only for tobacco consumption, 33 individuals were aged over 60 years and 14 individuals were aged above 18 years. Of the 304 individuals eligible for the study, 128 attended for the evaluation scheduling and agreed to participate by signing the Informed Consent and Informed (IC).

Data collection was carried out by means of the Global Appraisal of Individual Needs - GAIN Assessment Building System, the GAIN ABS, an online application for entering data collected at the time of implementation of GAIN-SS instrument, which facilitates the creation of clinical reports, diagnostic and transfer of the data collected for later statistical analyzes ${ }^{(13)}$. Clinical and diagnostic reports generated by the system were printed and attached to the records of those interviewed, as a means of immediate feedback on the study to respondents, and to help in the preparation of the unique therapeutic project by the professionals of the CAPSad. The data collected through the GAIN ABS were transferred to the Statistical Package for the Social Sciences (SPSS) program, Statistics 20 version.

\footnotetext{
* The Portuguese version of the GAIN-SS can be accessed, for example, at: http://goo.gl/28BP2c

** The individuals were interviewed by the researchers in an average time of 12 minutes, with a minimum of 3 minutes; $50 \%$ of the interviews were performed in less than 10 minutes.
} 
To verify the associations between the variables of symptoms and related problems in the areas of use of $A O D$, mental health and crime and violence, univariate and multiple ordinary least squares regression models (Ordinary Least Squares - OLS) were carried out. The purpose of a OLS regression is to draw a line that aims to predict a response variable (dependent variable), from one or more explanatory variables (independent variables) that minimize the sum of squared errors ${ }^{(14)}$.

One of the conditions necessary for an OLS regression analysis is that there is a linear relationship represented by $y_{-} i=\alpha+\beta x \_i+e_{-} i$, which shows how an average response ( $y \_i$ dependent variable) varies according to a vector of $\mathrm{x} \_\mathrm{i}$ independent variables with $\alpha$ intercept, $\beta$ inclination vector (slope) and e_i error term $^{(14)}$.

It was analyzed, as dependent variables, the symptoms related to the use of AOD, and as independent variables: gender, age, symptoms related to mental health (which includes internalizing and externalizing symptoms), problems related to crimes or other legal complications with which the customer may be involved, and situations of violence).

Univariate regressions for each independent variable were carried out, and those that achieved significance level less than or equal to 0.3 were maintaned in the multiple model, using the stepwise approach.

\section{Results}

Most interviewees were male, 85.2\% (109 individuals). The symptoms most frequently reported by the sample of respondents, in relation to mental health, were those related to internalization and those related to the use of AOD (3.73 symptoms on average) (Table 1).

Table 1 - Characterization of the research indivíduals. São Paulo, SP, Brazil, 2014

\begin{tabular}{|c|c|c|c|c|c|c|c|}
\hline \multirow{2}{*}{ Variables } & \multirow{2}{*}{ Mean } & \multicolumn{2}{|c|}{ Confidence interval 95\% } & \multirow{2}{*}{ Median } & \multirow{2}{*}{$\begin{array}{l}\text { Standard } \\
\text { Deviation }\end{array}$} & \multirow{2}{*}{ Minimum } & \multirow{2}{*}{ Maximum } \\
\hline & & Lower limit & Upper limit & & & & \\
\hline Age & 36.79 & 34.94 & 38.63 & 36.00 & 10.547 & 10 & 60 \\
\hline Interview duration (min) & 12.71 & 10.92 & 14.50 & 10.00 & 10.229 & 3 & 80 \\
\hline Symptoms of IDScr* & 3.05 & 2.72 & 3.39 & 3.00 & 1.900 & 0 & 6 \\
\hline Symptoms of EDScr ${ }^{\dagger}$ & 2.10 & 1.79 & 2.41 & 2.00 & 1.756 & 0 & 7 \\
\hline Symptoms of SDScr ${ }^{\ddagger}$ & 3.73 & 3.49 & 3.98 & 4.00 & 1.389 & 0 & 5 \\
\hline Problems of CVScr§ & 1.01 & .81 & 1.20 & 1.00 & 1.105 & 0 & 5 \\
\hline Symptoms TDScr" & 9.90 & 9.11 & 10.69 & 9.50 & 4.503 & 0 & 22 \\
\hline Gender & $\mathrm{n}$ & $\%$ & & & & & \\
\hline Male & 109 & 85.2 & & & & & \\
\hline Female & 19 & 14.8 & & & & & \\
\hline Total & 128 & 100.0 & & & & & \\
\hline
\end{tabular}

* Number of symptoms reported in the last 90 days. Maximum 6 symptoms.

+ Number of symptoms reported in the last 90 days. Maximum 7 symptoms.

₹ Number of symptoms reported in the last 90 days. Maximum 5 symptoms.

$\S$ Number of problems reported in the last 90 days. Maximum 5 symptoms.

II Number of problems reported in the last 90 days. Maximum 23 symptoms.

OLS regression models were designed to test the hypothesis that internalizing, externalizing symptoms (characterized by attention deficit, hyperactivity disorder and conduct disorder), problems related to crime and violence, age and gender are correlated with symptoms of reports of use of AOD.

Table 2 shows that, in relation to the dependent variable, the variables internalizing symptoms, externalizing symptoms and crime and violence are signicant. These variables, which have value $p \leq 0.3$, were included in the multiple model, since they present suggestive correlation with the dependent variable, symptoms related to the use of $A O D$, according to measurement of these items by the GAIN-SS instrument. The univariate models indicate which variables should be explored in the multiple model, to verify the correlation. In these models, only the variables gender and age have been removed, since they present $p$ value higher than the stipulated limit (0.3). 
Table 2 - Univariate models for symptoms related to the use of AOD (dependent variable). São Paulo, SP, Brazil, 2014

\begin{tabular}{lccccc}
\hline \multicolumn{1}{c}{ Variables } & $\begin{array}{c}\text { Coefficient B } \\
\text { (non-standard) }\end{array}$ & $\begin{array}{c}\text { Standard } \\
\text { error }\end{array}$ & $\begin{array}{c}\text { Beta Coefficient } \\
\text { (standard) }\end{array}$ & $\begin{array}{c}\text { Significance } \\
\text { ( } \mathbf{p} \text {-value) }\end{array}$ \\
\hline (Constant) & 2.976 & .220 & & 13.523 & $\leq 0.001^{*}$ \\
Internalizing symptoms & .248 & .061 & .340 & 4.054 & $\leq 0.001^{*}$ \\
(Constant) & 3.228 & .183 & & 17.592 & $\leq 0.001^{*}$ \\
Externalizing symptoms & .241 & .067 & .305 & 3.594 & $\leq 0.001^{*}$ \\
(Constant) & 3.310 & .157 & & 21.020 & $\leq 0.001^{*}$ \\
Crime and violence & .421 & .106 & .335 & 3.990 & $\leq 0.001^{*}$ \\
(Constant) & 3.731 & .417 & & 8.953 & $\leq 0.001^{*}$ \\
Gender & .003 & .347 & .001 & .008 & .993 \\
(Constant) & 4.378 & .445 & & 9.842 & $\leq 0.001^{*}$ \\
Age & -.017 & .012 & -.133 & -1.505 & .135 \\
\hline
\end{tabular}

* Significant $p \leq 0.01$

The variables internalizing symptoms, problems related to crime and violence and externalizing symptoms were included in the multiple model, since they present $p$-value $\leq 0.3$ (Table 3 ). The variables age and gender were not included.

In the multiple model (Table 3 ), the variables internalizing symptoms $(p$-value $=0.013)$ and problems related to crime and violence $(p$-value $=0.035)$ remained significant. The variable externalizing symptoms ( $p$-value $=0.683$ ) did not show significance at the multiple model, remaining in the model as control variable.
It is observed (Table 3 ) that the variables internalizing symptoms and problems related to crime and violence are positively correlated regarding the symptoms related to the use of $A O D$, with independent effect to the externalizing symptoms (not significant at the multiple model). In other words, there is a positive effect of increased reporting of internalizing symptoms and problems related to crime and violence, the reports of symptoms related to the use of $A O D$, regardless of the amount of externalizing symptoms reported.

Table 3 - Multiple model for the correlation between symptoms related to the use of AOD (dependent variable), internalizing symptoms, externalizing symptoms, problems related to crime and violence. São Paulo, SP, Brazil, 2014

\begin{tabular}{lcccc}
\hline \multicolumn{1}{c}{ Variables } & $\begin{array}{c}\text { Coefficient B } \\
\text { (non-standard) }\end{array}$ & $\begin{array}{c}\text { Standard } \\
\text { error }\end{array}$ & $\begin{array}{c}\text { Beta Coefficient } \\
\text { (standard) }\end{array}$ & $\begin{array}{c}\text { Significance } \\
\text { (p-value) }\end{array}$ \\
\hline (Constant) & 2.928 & .506 & & 5.789 \\
Internalizing symptoms & .176 & .067 & .241 & 2.623 \\
Externalizing symptoms & .061 & .081 & .077 & $.010^{*}$ \\
Crime and violence & .281 & .120 & .223 & .458 \\
\hline
\end{tabular}

* Significant $\mathrm{p} \leq 0.01$

+ Significant $p \leq 0.05$

For the individuals studied, the greater the report of internalizing symptoms and problems related to crime and violence, the greater the number of symptoms related to the use of AOD they have. This shows that increased severity (as evidenced by the increase in the number of symptoms and problems that individual suffering reports) is related to increased severity of the problems related to the use of AOD.

\section{Discussion}

The results allow stating that, with the increasing reports of internalizing symptoms and problems related to crime and violence, increase of symptoms related to the use of AOD is also observed.

The correlation between the experience of individuals with internalization problems and different levels and effects of consumption due to the use of AOD has already been described in the literature and, it has also been emphasized the important association between bipolar disorder, for example, with the use of AOD and smoking(15-16).

The most severe cases, resulting in significantly longer hospitalizations, are found in people who have symptoms related to guilt, low self-esteem and shame, compatible with the internalizing 
symptoms, and who are in treatment for abuse of $\operatorname{AOD}^{(17)}$.

The adult users of AOD, described in studies in which the GAIN-I (complete biopsychosocial assessment) was used, were more likely to present comorbidities such as tendency to internalizing symptoms and diagnosis of substance addiction ${ }^{(4,11)}$. This corroborates the results of this research, which correlate the increase in internalizing symptoms and symptoms related to the use of AOD, and that used the GAIN-SS instrument.

The correlation between the externalization symptoms, such as conduct disorder, for example, and the use of AOD, has also been mentioned in the literature(18). In this study, although significant in the univariate analysis, externalizing symptoms did not showed significant effect regardless of the internalizing symptoms and problems related to crime and violence.

Therefore, it can be inferred that problems related to the use of substance and their association with psychiatric disorders are common. Mood disorders such as depression, anxiety disorders (internalizing symptoms) and conduct disorders, attention deficit and hyperactivity disorder (externalizing symptoms) are the most common comorbidities associated with abuse of psychoactive substances ${ }^{(19)}$.

Problems related to crimes and violence are also constantly associated with the use of $\operatorname{AOD}^{(20-21)}$. In a study with a sample of 1,114 drug users, $70 \%$ of women and $66 \%$ of men reported some type of aggression in a follow-up study in a period of five years ${ }^{(22)}$.

The relationship between violence and disorders related to substance use has been discussed for over two decades, and one of the most significant contributors to violence is the abuse of AOD. In addition to interpersonal aggression, harmful behaviors against oneself (eg, suicidal ideation, suicide attempts, suicides, etc.) are also associated with psychiatric disorders ${ }^{(19,23)}$, either with internalizing or externalizing symptoms, demonstrating the important correlation between the symptomatology of internalizing or externalizing, disorder due to the use of AOD and problems related to crime and violence.

Factors such as increased aggressiveness, impulsivity and hostility raised the possibility of association between suicide and disorders related to substance use among patients with bipolar disorder, and those related to substance use when compared to those without these disorders ${ }^{(24)}$.

There is a large number of users of AOD, who have mental disorders such as comorbidities. This association has been researched over time, since the comorbidity between mental disorders and disorders related to substance use increases the risk of violent conduct. Individuals with multiple diagnoses are, as result of substance abuse, more likely to have treatment problems, no adherence to medication, increased length of stay in the service, poor quality of life and worst treatment results $(4,11)$.

Due to the results achieved here, it is believed that treatment programmes focused on disorders related to substance use, may be an appropriate context to identify the psychiatric comorbidity and presence of general violent behaviors and partner violence.

To identify comorbidities and problems related to crime and violence and to study their impact on the progress of treatment may help the health professionals to treat the two problems simultaneously and, thus, to help to improve the results of the existing treatment programs.

These results are relevant because interpersonal violence can interfere with the progress of treatment and maintenance of abstinence in substances ${ }^{(25)}$. Similarly, the presence of psychiatric comorbidities may increase the use of AOD.

Therefore, it is possible stating that the use of AOD has economic and social impact. Any measures aiming at a more efficient investment of public resources and reduction of costs in this area are necessary to confront this issue. Accordingly, it is reinforced the importance of investments in the screening, proper allocation and more individualized treatments based on scientific evidence. It is noteworthy also the importance of strategies to prevent the use or conditions of use in the populations, as well as prevention and treatment of diseases and morbidities associated with chemical dependency.

As limitations of this study, it is emphasized that data collection was performed at only one service in the city of Sao Paulo, which does not allow generalizations. The study is also limited to the age group between 18 and 60 years. Future studies should include the elderly and adolescent population, as well as the use of this instrument in other cities, in order to verify its performance.

\section{Conclusions}

It is verified that the number of symptoms related to the use of AOD, reported by the individuals, presents statistically significant correlation with the number of mental health symptoms related to internalizing 
symptoms and problems related to crime and violence, showing the importance of working together these different problems in order to reduce the vulnerability of the users of AOD.

The results emphasize the need for an interdisciplinary and intersectoral intervention focused on the attention to the user of AOD, since they live in a socially vulnerable environment.

Future research is needed to establish the mechanisms responsible for the associations between substance abuse, mental illness and violence, since the cross-sectional nature of the data prevents us from determining causality.

\section{Acknowledgements}

To Ricardo Willians, Mike Vacca, Michael Dennis, Sandra McGuinness, Laine Twanow and Francesca McKean, for their support. To Thais Fernandes Rojas, for her help in drafting the manuscript, and to Thaís Pereira, João Braga and Marcelo Melo and his team, for enabling collection of the data presented.

\section{References}

1. WHO. Global status report on alcohol and health. Geneva: World Health Organization; 2011. 286 p.

2. Gallassi AD, Alvarenga PGd, Andrade AGd, Couttolenc BF. The cost of problems caused by alcohol abuse. Rev Psiquiatr Clín. 2008;35(supl 1):6.

3. Carlini E, Galduróz J, Noto A, Carlini C, Oliveira L, Nappo A. II Levantamento Domiciliar sobre o uso de drogas psicotrópicas no Brasil: Envolvendo as 108 maiores cidades do país. Brasília - Distrito Federal: Centro Brasileiro de Informação sobre Drogas CEBRID; 2005.

4. Paglione HB, Claro HG, Oliveira MAF, Titus J, Lima M, Pereira TC. Contribuições do instrumento "Global Appraisal of Individual Needs" para a assistência e pesquisa: revisão da literatura. Rev Terap Ocup Univ de São Paulo. 2012;23(1):81-8.

5. Chisholm D, Saxena S, Ommeren Mv, World Health Organization. Dept. of Mental Health and Substance Abuse. Dollars, DALYs and decisions : economic aspects of the mental health system. Geneva: World Health Organization; 2006. 56 p.

6. Funk M, Drew N, Freeman M, Faydi E, World Health Organization. Mental health and development : targeting people with mental health conditions as a vulnerable group. Geneva: World Health Organizations; 2010. 74 p.
7. Santos MJD, Kassouf AL. Uma Investigação Econômica da Influência do Mercado de Drogas Ilícitas Sobre a Criminalidade Brasileira. Rev EconomiA. 2007;8(2):187-210.

8. Pereira OA Filho, Tannuri-Pianto ME, Sousa MdCSd. Medidas de custo-eficiência dos serviços subnacionais de segurança pública no Brasil: 2001-2006. Econo Apl. 2010;14:313-38.

9. Dennis M, Feeney T, Stevens L, Bedoya L. Global Appraisal of Individual Needs - Short Screener (GAINSS): Administration and Scoring Manual. Normal Illinois: Chestnut Health Systems; 2008.

10. Claro HG. Validação dos Instrumentos "Avaliação Global das Necessidades Individuais - Inicial e Rastreio Rápido". [Tese]. São Paulo: Escola de Enfermagem da Universidade de São Paulo; 2015.

11. Dennis $M$, Chan $Y$, Funk R. Development and validation of the GAIN Short Screener (GSS) for internalizing, externalizing and substance use disorders and crime/violence problems among adolescents and adults. Am J Addict. 2006;15 Suppl 1:80-91.

12. Ministério da Saúde (BR). Portaria GM n. 336, de 19 de fevereiro de 2002. Dispõe sobre a constituição dos Centros de Atenção Psicossocial. $4^{a}$ ed. Brasília: Ministério da Saúde; 2004.

13. Dennis M, White M, Titus J, Unsicker J. Global Appraisal of Individual Needs: Administration Guide for the GAIN and related Measures [Internet]. [Acesso $15 \mathrm{dez} 2013$ ]; Bloomington (IL); 2003. Disponível em: http://pubs.niaaa.nih.gov/ publications/AssessingAlcohol/InstrumentPDFs/37_GAIN.pdf 14. Baldi $B$, Moore DS. The practice of statistics in the life sciences: WH Freeman; 2014.

15. Sher KJ, Martinez JA, Littlefield AK. Alcohol Use and Alcohol Use. Oxford Handbook of Clinical Psychology: Updated Edition. Oxford; 2014. p. 410.

16. Wilens TE, Zulauf CA. Substance use in youth with bipolar disorder [Internet]. Clin Insights: Mental Health Adolesc: Bipolar Disorder. [Acesso 16 jun 2014]. Boston; 2014 Feb. p. 57-74. Disponível em: http://www.futuremedicine.com/ doi/abs/10.2217/ebo.13.557. Doi: 10.2217/ebo.13.557

17. Luoma JB, Kulesza M, Hayes SC, Kohlenberg B, Larimer $M$. Stigma predicts residential treatment length for substance use disorder. Am J Drug Alcohol Abuse. 2014;40(3):206-12.

18. King SM, Iacono WG, McGue M. Childhood externalizing and internalizing psychopathology in the prediction of early substance use. Addiction. 2004;99(12):1548-59.

19. Borowsky IW, Ireland M, Resnick MD. Adolescent suicide attempts: risks and protectors. Pediatrics. 2001;107(3):485-93. 
20. Clements K, Schumacher JA. Perceptual biases in social cognition as potential moderators of the relationship between alcohol and intimate partner violence: A review. Aggress Violent Behav. 2010;15(5):357-68.

21. Montalvo JF, Goñi JJL, Arteaga A. Tratamiento de agresores contra la pareja en programas de atención a drogodependientes: un reto de futuro. Adicciones: Rev Socidrogalcohol. 2011;23(1):5-9.

22. Marshall BD, Fairbairn N, Li K, Wood E, Kerr T. Physical violence among a prospective cohort of injection drug users: a gender-focused approach. Drug and Alcohol Dependence. 2008;97(3):237-46.

23. Harris EC, Barraclough B. Suicide as an outcome for mental disorders. A meta-analysis. Br J Psychiatry. 1997;170(3):205-28.

24. Dennis M, Dawud-Noursi S, Muck R, McDermeit $M$. The need for developing and evaluating adolescent treatment models. Adolescent substance abuse treatment in the United States: Exemplary Models from a National Evaluation Study. Binghamton, NY: Haworth Press; 2002. p. 3-34.

25. Schneider R, Timko C. Does a history of violence influence treatment, self-help, and 1-year outcomes in substance use disorder patients? J Addict Dis. 2009;28(2):171-9.

\section{Erratum}

On page 1173 , that read:

"Janet Titus Bourdreaux"

Read:

"Janet C. Titus"

Rev. Latino-Am. Enfermagem. 2016;24:e2666 